\title{
The Age-Related Orientational Changes of Human Semicircular Canals
}

\author{
Hui-Ying Lyu ${ }^{1} \cdot$ Ke-Guang Chen ${ }^{1}$ D Dong-Ming Yin ${ }^{1} \cdot$ Juan Hong ${ }^{1} \cdot$ Lin Yang $^{2,3} \cdot$ Tian-Yu Zhang ${ }^{1,3} \cdot$ Pei-Dong Dai ${ }^{2,3}$ \\ ${ }^{1}$ Department of Otolaryngology, ${ }^{2}$ Research Center, Eye and ENT Hospital, Fudan University, Shanghai; \\ ${ }^{3}$ Key Laboratory of Hearing Medicine, National Ministry of Public Health, Shanghai, China
}

Objectives. Some changes are found in the labyrinth anatomy during postnatal development. Although the spatial orientation of semicircular canals was thought to be stable after birth, we investigated the age-related orientational changes of human semicircular canals during development.

Methods. We retrospectively studied the computed tomography (CT) images of both ears of 76 subjects ranged from 1 to 70 years old. They were divided into 4 groups: group A (1-6 years), group B (7-12 years), group C (13-18 years), and group D (>18 years). The anatomical landmarks of the inner ear structures were determined from CT images. Their coordinates were imported into MATLAB software for calculating the semicircular canals orientation, angles between semicircular canal planes and the jugular bulb (JB) position. Differences between age groups were analyzed using multivariate statistics. Relationships between variables were analyzed using Pearson analysis.

Results. The angle between the anterior semicircular canal plane and the coronal plane, and the angle between the horizontal semicircular canal plane and the coronal plane were smaller in group $\mathrm{D}$ than those in group $\mathrm{A}(P<0.05)$. The $\mathrm{JB}$ position, especially the anteroposterior position of right JB, correlated to the semicircular canals orientation $(P<0.05)$. However, no statistically significant differences in the angles between ipsilateral canal planes among different age groups were found.

Conclusion. The semicircular canals had tendencies to tilt anteriorly simultaneously as a whole with age. The JB position correlated to the spatial arrangement of semicircular canals, especially the right JB. Our calculation method helps detect developmental and pathological changes in vestibular anatomy.

Keywords. Semicircular Canals; Orientation; Anatomy; Tomography, X-Ray Computed; Jugular Bulb

\section{INTRODUCTION}

The semicircular canals which perceive the head rotation and angular acceleration sit deeply in the petrous temporal bone. Up to now, several authors have well reported the geometry and spatial relationships of human semicircular canals [1,2]. Their size and orientation are linked with the vestibular function, and the latter

- Received December 23, 2014

Revised March 13, 2015

Accepted June 10, 2015

- Corresponding author: Pei-Dong Dai

Research Center, Eye and ENT Hospital, Fudan University, 83 Fenyang

Road, Shanghai 200031, China

Tel: +86-21-64377134-634, Fax: +86-21-64377151

E-mail: peters818@aliyun.com is more critical to locomotor agility than the former [3,4].

While prenatal development of human semicircular canals was studied, and some changes in semicircular canals size and orientation were found by some researchers [5], postnatal semicircular canals development is more debated. It was believed that the morphology and spatial orientation of semicircular canals did not change significantly after birth. It now appears that the bimodal growth of cranium occurring during infancy and then again during puberty may have significant impact on the labyrinth anatomy, for instance, the cochlear orientation in children is different from that in adults [6]. However, current work on the postnatal changes in semicircular canals orientation is still very limited. We supposed that human semicircular canals orientation may change during postnatal development. Addi-

Copyright (C) 2016 by Korean Society of Otorhinolaryngology-Head and Neck Surgery.

This is an open-access article distributed under the terms of the Creative Commons Attribution Non-Commercial License (http://creativecommons.org/licenses/by-nc/4.0)

which permits unrestricted non-commercial use, distribution, and reproduction in any medium, provided the original work is properly cited. 
tionally, these changes may be related to the asynchronous development of cranial base.

To test our hypothesis, high-resolution computed tomography (CT) images of 152 normal temporal bones of 76 human subjects were reviewed. Semicircular canals orientation within the cranial base was calculated, and its relationships with the jugular bulb (JB) and mastoid processes were analyzed. The acquired data may be helpful in elucidating age-related orientational changes of human semicircular canals during postnatal development.

\section{MATERIALS AND METHODS}

\section{Subjects}

We retrospectively studied the $\mathrm{CT}$ images of both temporal bones of nearly 200 patients who were randomly selected and were investigated for hearing loss, tinnitus and other complaints in our hospital from January 2006 to April 2012. No subject had a complaint of vertigo or dizziness. The anatomies of all temporal bones of 76 subjects were assessed as normal by radiologists. There were 25 males of $22.7 \pm 16.2$ years old (range, 1 to 58 years) and 51 females of $26.4 \pm 18.41$ years old (range, 1 to 70 years).

The cranial base grows rapidly after birth and slows down gradually after the 6th year, and then undergoes another growth curve during puberty $[7,8]$. Considering the possible impact of the cranial growth on semicircular canals anatomy, the subjects were divided into 4 age groups: group A (1-6 years old, $n=14,6$ males, 8 females), group B (7-12 years old, $n=10,3$ males, 7 females), group $\mathrm{C}$ (13-18 years old, $\mathrm{n}=7,2$ males, 5 females) and group $\mathrm{D}$ ( $>18$ years old, $\mathrm{n}=45,14$ males, 31 females).

\section{Data acquisition}

All axial images were taken with multidetector row CT (Sensation 16, Siemens Medical Systems, Erlangen, Germany) in helical mode. Our scanning procedure followed the standard temporal bone imaging protocol. Scans were acquired with a tube voltage of $120.0 \mathrm{kV}$ and a current of $180.0 \mathrm{~mA}$. The images were reconstructed with 0.75 -mm-thick sections at 0.5 -mm increment, a $512 \times 512$ matrix of $0.43-\mathrm{mm}$ pixel size and a FOV of $22.0 \mathrm{~cm} \times 22.0 \mathrm{~cm}$. These images were displayed at a window center of $700 \mathrm{HU}$ and a window width of 4,000 HU.

\section{Postprocessing}

CT DICOM images contain positioning data which defines the spatial coordinate in the superoinferior, anteroposterior and leftright directions. These images were observed in MIMICS 12.1 (Materialize, Leuven, Belgium) with a contrast scale between $-1,024 \mathrm{HU}$ (air) and 2,000 HU (bone). A series of 3-dimensional anatomical landmarks of temporal bones were taken from these images using this software.

It is difficult to ensure the subjects hold their heads in precisely the same position and orientation during the CT image acqui-

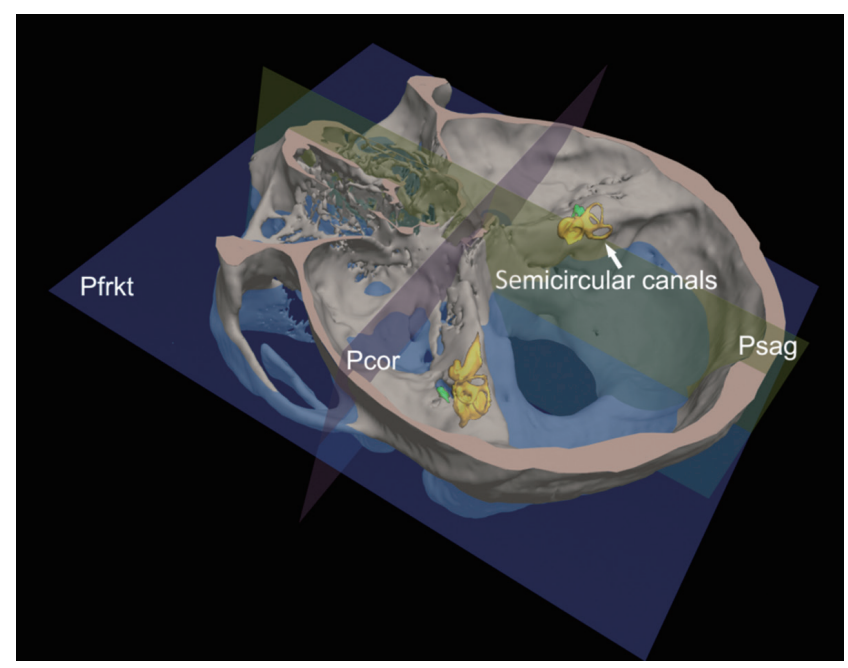

Fig. 1. Standard 3-dimensional coordinate system relative to cranial base we developed. The semicircular canals (arrow) deeply located in the petrous bones. Pfrkt, Frankfurt horizontal plane; Psag, median sagittal plane; Pcor, coronal plane.

sition. To ensure the accuracy of our calculation of semicircular canals orientation within the cranial base, we developed a standard 3-dimensional coordinate system which was defined by the Frankfurt horizontal plane (Pfrkt) and its perpendicular planes [9]. This system was based upon anatomical landmarks and independent of the subject head positioning during the CT examination. As a conventional reference plane in anthropometry, the Pfrkt plane is defined to pass through the left orbitale point (the left inferior orbital margin) and bilateral porion points (the superior margins of bilateral external auditory canals). The median sagittal plane (Psag) was defined as a plane passing through the top of the crista galli [10] and the midpoint of the line connecting the tips of bilateral posterior clinoid processes [9] and lying perpendicular to the Pfrkt plane. The coronal plane (Pcor) was defined as a plane passing through the midpoint of the line connecting the tips of bilateral posterior clinoid processes and lying perpendicular to both Pfrkt and Psag (Fig. 1).

The ampullar and slender parts of semicircular canals and the common crus were studied in our calculation. The semicircular canal planes were defined by three anatomical landmarks for each canal [11]: the ampulla-side end, the non-ampulla-side end (or the bifurcation-side end for the vertical canals) and the extreme point for each canal. These landmarks included the centroids of cross sections of ampullary orifices of the anterior, posterior and horizontal semicircular canals, the centroid of cross section of nonampullary orifice of the horizontal semicircular canal, the centroid of cross section of orifice of the common crus, the bifurcation point of the common crus, and the superiormost, posterior-most and lateral-most points of the anterior, posterior and horizontal semicircular canals, respectively. The landmark of the JB was defined as the upmost point of the bulb [12]. Abbreviations throughout the article were summarized in 


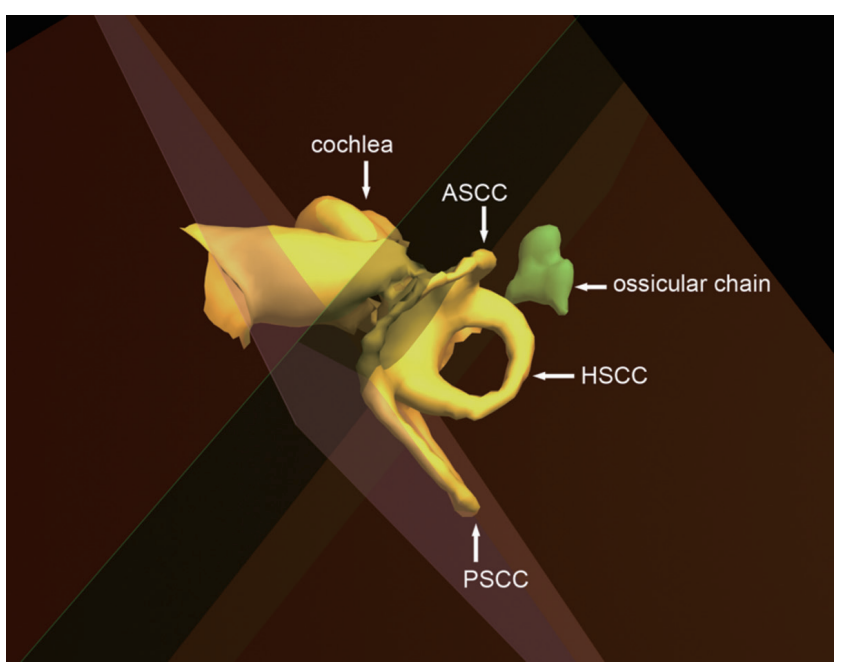

Fig. 2. Right inner ear and ossicular chain. The semicircular canal planes were represented by the planes passing through each canal. ASCC, anterior semicircular canal; PSCC, posterior semicircular canal; HSCC, horizontal semicircular canal.

the online-only supplement.

\section{Calculation}

The 3-dimensional coordinates (x, y, z) of each anatomical landmark were obtained from MIMICS. After that, coordinate values were imported into a self-developed calculation program LabyCalculation based on MATLAB software (MathWorks Inc., Natick, MA, USA). The point-to-plane distance and the angle between planes can be automatically calculated according to the analytical geometry using this software (for details see onlineonly supplement).

The spatial orientation of semicircular canals within the cranial base was defined as the angles between each canal and the standard reference planes (Fig. 2). $\angle \mathrm{A} / \mathrm{Pcor}, \angle \mathrm{A} / \mathrm{Pfrkt}$, and $\angle \mathrm{A} / \mathrm{Psag}$ referred to angles between the anterior semicircular canal plane and the Pcor, Pfrkt, and Psag, respectively. $\angle \mathrm{H} / \mathrm{Pcor}, \angle \mathrm{H} / \mathrm{Pfrkt}$, and $\angle \mathrm{H} /$ Psag referred to angles between the horizontal semicircular canal plane and the Pcor, Pfrkt, and Psag, respectively. $\angle \mathrm{P} /$ Pcor, $\angle \mathrm{P} /$ Pfrkt, and $\angle \mathrm{P} /$ Psag referred to angles between the posterior semicircular canal plane and the Pcor, Pfrkt, and Psag, respectively. Angels between semicircular canal planes included angles between ipsilateral canal planes and between opposite synergistically acting canal planes (Fig. 3). $\angle \mathrm{ipsiA} / \mathrm{ipsiH}$ referred to angle between anterior and ipsilateral horizontal semicircular canals. $\angle \mathrm{ipsiA} / \mathrm{ipsiP}$ referred to angle between anterior and ipsilateral posterior semicircular canals. $\angle \mathrm{ipsiH} / \mathrm{ipsiP}$ referred to angle between horizontal and ipsilateral posterior semicircular canals. $\angle$ leftA $/$ rightP referred to angle between left anterior and right posterior semicircular canals. $\angle$ rightA/ leftP referred to angle between right anterior and left posterior semicircular canals. $\angle$ rightH/ leftH referred to angle between bilateral horizontal semicircular canals. These angles were positive and ranged from

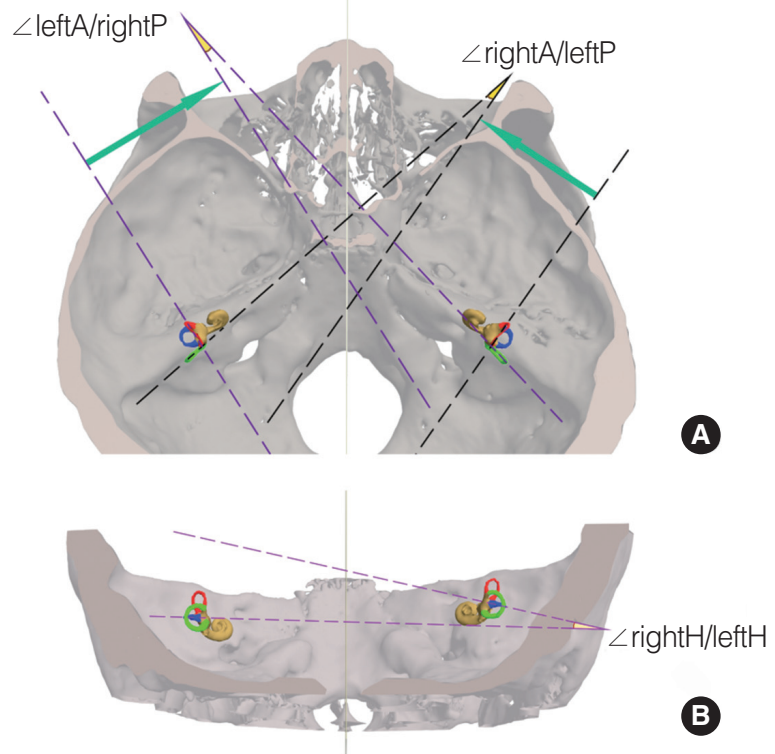

Fig. 3. The angles between contralateral synergistic canals. Panel A is apical view. Panel $B$ is posterior view. The anterior, posterior, and horizontal semicircular canals are red, green and blue colored, respectively. $\angle$ indicate the angle between 2 planes; $A, P$, and $H$, indicate the anterior, posterior, and horizontal semicircular canal plane, respectively.

$0^{\circ}$ to $180^{\circ}$.

The JB position in the cranial base was defined as its distances from Pcor, Pfrkt, and Psag planes (JB-Pcor, JB-Pfrkt, and JBPsag), respectively. Its superoinferior position was expressed as positive value if it was located over the Pfrkt plane, and negative if under this plane. The mastoid air cells were reconstructed with a lower threshold of $-1,024 \mathrm{HU}$ and an upper threshold of -200 HU.The volume of mastoid air cells were automatically calculated by MIMICS.

All calculations in this study were practiced by a single investigator.

\section{Statistical analysis}

Differences among age groups were analyzed using Kruskal-Wallis test with Bonferroni correction $(P<0.05)$. Relationships between semicircular canals orientation and JB position were analyzed using Pearson analysis $(P<0.05)$. The data analysis was performed by Stata 10.0 (StataCorp LP., College Station,TX, USA).

\section{RESULTS}

As seen in Table $1, \angle \mathrm{A} /$ Pcor and $\angle \mathrm{H} / \mathrm{Pcor}$ had tendencies to decrease with age and were smaller in adults (group $D$ ) than those in young children (group A) $(P<0.05)$. Moreover, $\angle \mathrm{P} /$ Pcor still showed a nonsignificant tendency to decrease with age. These findings suggested that semicircular canals tilted anteriorly with age.

As seen in Table 2, the JB position had statistically significant correlation with semicircular canals orientation. There were neg- 
Table 1. Differences of semicircular canals orientation among age groups (degree)

\begin{tabular}{|c|c|c|c|c|c|c|c|c|c|c|c|c|}
\hline Plane & Side & Group A $(n=14)$ & Group B $(n=10)$ & Group C (n=7) & Group D $(n=45)$ & $P$ & $P_{a b}$ & $P_{\mathrm{ac}}$ & $P_{\text {ad }}$ & $P_{\mathrm{bc}}$ & $P_{\mathrm{bd}}$ & $P_{c d}$ \\
\hline \multirow[t]{2}{*}{$\angle \mathrm{A} / \mathrm{Psag}$} & L & $23.60 \pm 5.79$ & $25.09 \pm 3.37$ & $27.94 \pm 5.09$ & $26.17 \pm 4.32$ & NS & - & - & - & - & - & - \\
\hline & $\mathrm{R}$ & $25.42 \pm 5.56$ & $24.98 \pm 4.03$ & $28.30 \pm 3.39$ & $27.46 \pm 4.20$ & NS & - & - & - & - & - & - \\
\hline \multirow[t]{2}{*}{$\angle \mathrm{A} /$ Pcor } & L & $84.91 \pm 22.76$ & $76.51 \pm 18.62$ & $71.49 \pm 16.27$ & $69.00 \pm 12.70$ & $<0.01$ & NS & NS & $<0.01$ & NS & NS & NS \\
\hline & $\mathrm{R}$ & $83.14 \pm 22.70$ & $77.41 \pm 19.25$ & $72.83 \pm 17.42$ & $68.41 \pm 13.25$ & $<0.01$ & NS & NS & $<0.05$ & NS & NS & NS \\
\hline \multirow[t]{2}{*}{$\angle \mathrm{A} /$ Pfrkt } & L & $82.57 \pm 4.46$ & $80.58 \pm 6.94$ & $84.00 \pm 14.16$ & $83.41 \pm 7.09$ & NS & - & - & - & - & - & - \\
\hline & $R$ & $79.08 \pm 3.87$ & $81.25 \pm 7.88$ & $82.73 \pm 14.33$ & $81.88 \pm 7.25$ & NS & - & - & - & - & - & - \\
\hline \multirow[t]{2}{*}{$\angle \mathrm{P} / \mathrm{Psag}$} & L & $44.68 \pm 4.30$ & $44.14 \pm 7.87$ & $43.61 \pm 4.91$ & $43.55 \pm 4.68$ & NS & - & - & - & - & - & - \\
\hline & $\mathrm{R}$ & $44.47 \pm 5.73$ & $43.41 \pm 5.83$ & $42.40 \pm 5.81$ & $42.50 \pm 5.31$ & NS & - & - & - & - & - & - \\
\hline \multirow[t]{2}{*}{$\angle \mathrm{P} /$ PcorL } & L & $70.46 \pm 40.51$ & $63.87 \pm 33.29$ & $63.08 \pm 32.19$ & $55.67 \pm 20.63$ & NS & - & - & - & - & - & - \\
\hline & $\mathrm{R}$ & $71.29 \pm 40.68$ & $63.47 \pm 30.96$ & $63.17 \pm 31.06$ & $56.45 \pm 19.90$ & NS & - & - & - & - & - & - \\
\hline \multirow[t]{2}{*}{$\angle \mathrm{P} /$ PfrktL } & L & $82.36 \pm 3.88$ & $82.45 \pm 13.24$ & $78.72 \pm 9.79$ & $79.03 \pm 10.24$ & $<0.05$ & NS & NS & $<0.05$ & NS & NS & NS \\
\hline & $\mathrm{R}$ & $82.27 \pm 4.77$ & $80.24 \pm 12.75$ & $79.71 \pm 9.94$ & $79.23 \pm 10.64$ & NS & - & - & - & - & - & - \\
\hline \multirow[t]{2}{*}{$\angle \mathrm{H} /$ Psag } & L & $86.25 \pm 2.84$ & $88.41 \pm 5.04$ & $90.58 \pm 7.41$ & $89.11 \pm 4.32$ & NS & - & - & - & - & - & - \\
\hline & $\mathrm{R}$ & $86.55 \pm 4.48$ & $89.87 \pm 4.43$ & $90.11 \pm 6.64$ & $89.82 \pm 4.47$ & NS & - & - & - & - & - & - \\
\hline \multirow[t]{2}{*}{$\angle \mathrm{H} /$ Pcor } & L & $85.40 \pm 12.66$ & $82.43 \pm 13.27$ & $78.63 \pm 16.20$ & $74.83 \pm 10.07$ & $<0.01$ & NS & NS & $<0.05$ & NS & NS & NS \\
\hline & $\mathrm{R}$ & $83.49 \pm 13.67$ & $82.02 \pm 16.70$ & $75.11 \pm 13.18$ & $73.91 \pm 10.57$ & $<0.05$ & NS & NS & $<0.05$ & NS & NS & NS \\
\hline \multirow[t]{2}{*}{$\angle \mathrm{H} /$ Pfrkt } & L & $13.43 \pm 3.58$ & $30.75 \pm 48.12$ & $37.67 \pm 51.93$ & $33.36 \pm 45.33$ & $<0.05$ & NS & NS & $<0.05$ & NS & NS & NS \\
\hline & $\mathrm{R}$ & $14.85 \pm 5.43$ & $31.76 \pm 45.77$ & $38.61 \pm 52.89$ & $33.72 \pm 44.72$ & NS & - & - & - & - & - & - \\
\hline
\end{tabular}

Values are presented as mean \pm SD.

Psag, median sagittal plane; Pcor, coronal plane; Pfrkt, Frankfurt horizontal plane; L, left; R, right; NS, not significant.

Groups A-D indicate 1-6, 7-12, 13-18, and $>18$ years old group, respectively; $P_{\mathrm{ab}}, P_{\mathrm{ac}}, P_{\mathrm{ad}}, P_{\mathrm{bc}}, P_{\mathrm{bd}}, P_{\mathrm{cd}}$ indicate $P$-value for differences between groups A and $B$, between groups $A$ and $C$, between groups $A$ and $D$, between groups $B$ and $C$, between groups $B$ and $D$, and between groups $C$ and $D$, respectively; $\angle$ indicate the angle between 2 planes; A, P, and $\mathrm{H}$ indicate the anterior, posterior, and horizontal semicircular canal plane, respectively.

Table 2. Correlation coefficients between semicircular canals orientation and ipsilateral JB position

\begin{tabular}{|c|c|c|c|c|c|c|c|c|c|c|}
\hline & Side & $\angle \mathrm{A} /$ Psag & $\angle \mathrm{A} /$ Pcor & $\angle \mathrm{A} / \mathrm{Pfrkt}$ & $\angle \mathrm{P} /$ Psag & $\angle \mathrm{P} /$ Pcor & $\angle \mathrm{P} / \mathrm{Pfrkt}$ & $\angle \mathrm{H} /$ Psag & $\angle \mathrm{H} /$ Pcor & $\angle \mathrm{H} /$ Pfrkt \\
\hline \multirow[t]{2}{*}{ JB-Psag } & L & 0.06 & - & - & 0.09 & - & - & 0.04 & - & - \\
\hline & R & -0.16 & - & - & 0.16 & - & - & $-0.42^{\star \star \star}$ & - & - \\
\hline \multirow[t]{2}{*}{ JB-Pcor } & L & - & $-0.29^{\star *}$ & - & - & 0.20 & - & - & -0.10 & - \\
\hline & $\mathrm{R}$ & - & $-0.26^{\star}$ & - & - & 0.19 & - & - & 0.06 & - \\
\hline \multirow[t]{2}{*}{ JB-Pfrkt } & L & - & - & -0.06 & - & - & $0.38^{\star \star *}$ & - & - & -0.12 \\
\hline & $\mathrm{R}$ & - & - & 0.03 & - & - & 0.11 & - & - & -0.14 \\
\hline
\end{tabular}

JB, jugular bulb; Psag, median sagittal plane; Pcor, coronal plane; Pfrkt, Frankfurt horizontal plane; Pcor, coronal plane; L, left; R, right.

$\angle$ indicate the angle between 2 planes; A, P, and $\mathrm{H}$ indicate the anterior, posterior, and horizontal semicircular canal plane, respectively; JB-Psag, JBPcor, and JB-Pfrkt: The JB position in the cranial base was defined as its distances from Psag, Pcor, and Pfrkt planes, respectively.

${ }^{\star} P<0.05 .{ }^{\star \star} P<0.01$. ${ }^{\star \star *} P<0.001$.

ative correlations between JB-Pcor and $\angle \mathrm{A} / \mathrm{Pcor}$ on both sides (on the left side, $r=-0.29, P<0.01$; on the right side, $r=-0.26$, $P<0.05)$, which means the more posteriorly the JB located, the more anteriorly the anterior semicircular canal tilted.

There were no statistically significant differences in angles between ipsilateral semicircular canal planes or angles between anterior and opposite posterior canal planes among age groups (Table 3). $\angle$ rightH/leftH was found to be smaller in group D than that in group C. However, the small sample size in group $\mathrm{C}$ may affect the reliability of this result. According to the information in Tables 1 and 3, we assumed that the semicircular canals tilted anteriorly simultaneously as a whole with age.

As seen in Table 4, there was a negative correlation between $\angle$ ipsiP/ipsiH and JB-Pcor on the right side $(r=-0.26, P<0.05)$. It suggested that the more anteriorly the right JB located, the larger angle between right posterior and right horizontal semicircular canals was.

Besides, the mean volumes of mastoid air cells in groups A, B, $\mathrm{C}$, and $\mathrm{D}$ were $5.78 \pm 2.03,9.76 \pm 4.35,12.28 \pm 5.12$, and $9.87 \pm$ $5.91 \mathrm{~mL}$, respectively. The volume of mastoid air cells in group A was smaller than that in groups $\mathrm{C}$ and $\mathrm{D}(P<0.05)$. However, no significant correlations between the volume of mastoid air cells and the spatial arrangement of semicircular canals were found in our study.

\section{DISCUSSION}

The postural balance control in human requires proper collaboration of somatosensory, visual and vestibular systems. Up to 
Table 3. Differences in the angles between ipsilateral semicircular canals and between opposite synergistically acting semicircular canals among age groups (degree)

\begin{tabular}{|c|c|c|c|c|c|c|c|c|c|c|c|c|}
\hline Plane & Side & Group A $(n=14)$ & Group B $(n=10)$ & Group C $(n=7)$ & Group D $(n=45)$ & $P$ & $P_{\mathrm{ab}}$ & $P_{\text {ac }}$ & $P_{\text {ad }}$ & $P_{\mathrm{bc}}$ & $P_{\mathrm{bd}}$ & $P_{\mathrm{cd}}$ \\
\hline \multirow[t]{2}{*}{$\angle$ ipsiA/ipsiH } & $L$ & $90.82 \pm 3.93$ & $86.78 \pm 5.03$ & $85.95 \pm 8.48$ & $89.36 \pm 5.08$ & NS & - & - & - & - & - & - \\
\hline & $\mathrm{R}$ & $87.86 \pm 5.03$ & $86.31 \pm 4.94$ & $85.37 \pm 4.34$ & $88.14 \pm 4.93$ & NS & - & - & - & - & - & - \\
\hline \multirow[t]{2}{*}{$\angle \mathrm{ipsiH} / \mathrm{ipsiP}$} & $L$ & $88.44 \pm 3.42$ & $85.60 \pm 4.49$ & $88.40 \pm 6.95$ & $86.88 \pm 4.64$ & NS & - & - & - & - & - & - \\
\hline & $\mathrm{R}$ & $89.24 \pm 6.10$ & $86.61 \pm 2.11$ & $88.66 \pm 5.10$ & $87.89 \pm 4.87$ & NS & - & - & - & - & - & - \\
\hline \multirow[t]{2}{*}{$\angle \mathrm{ipsiA} / \mathrm{ipsiP}$} & $L$ & $112.41 \pm 5.84$ & $111.56 \pm 6.95$ & $109.91 \pm 4.55$ & $108.45 \pm 15.47$ & NS & - & - & - & - & - & - \\
\hline & $\mathrm{R}$ & $111.22 \pm 6.46$ & $112.04 \pm 5.38$ & $110.64 \pm 5.73$ & $110.49 \pm 4.52$ & NS & - & - & - & - & - & - \\
\hline$\angle$ rightH/leftH & & $9.70 \pm 6.07$ & $9.17 \pm 4.50$ & $12.85 \pm 5.37$ & $7.50 \pm 4.23$ & $<0.05$ & NS & NS & NS & NS & NS & $<0.05$ \\
\hline$\angle$ leftA/rightP & & $22.13 \pm 9.36$ & $19.73 \pm 7.86$ & $18.88 \pm 7.72$ & $17.82 \pm 7.30$ & NS & - & - & - & - & - & - \\
\hline RightA/leftP & & $21.84 \pm 8.89$ & $21.64 \pm 7.88$ & $20.45 \pm 6.89$ & $17.33 \pm 6.13$ & NS & - & - & - & - & - & - \\
\hline
\end{tabular}

Values are presented as mean \pm SD.

ipsi, ipsilateral; L, left; R, right; NS, not significant.

Groups A-D indicate 1-6, 7-12, 13-18, and $>18$ years old group, respectively; $P_{\mathrm{ab}}, P_{\mathrm{ac}}, P_{\mathrm{ad}}, P_{\mathrm{bc}}, P_{\mathrm{bd}}, P_{\mathrm{cd}}$ indicate $P$-value for differences between groups A and $B$, between groups $A$ and $C$, between groups $A$ and $D$, between groups $B$ and $C$, between groups $B$ and $D$ and between groups $C$ and $D$, respectively; $\angle$ indicate the angle between 2 planes; $\mathrm{A}, \mathrm{H}$, and $\mathrm{P}$ indicate the anterior, horizontal, and posterior semicircular canal plane, respectively.

Table 4. Correlation coefficients between JB position and angles between ipsilateral semicircular canals

\begin{tabular}{|c|c|c|c|c|c|c|}
\hline \multirow{2}{*}{ Plane } & \multicolumn{2}{|c|}{ JB-Psag } & \multicolumn{2}{|c|}{ JB-Pcor } & \multicolumn{2}{|c|}{ JB-Pfrkt } \\
\hline & L & $\mathrm{R}$ & L & $\mathrm{R}$ & L & $\mathrm{R}$ \\
\hline$\angle \mathrm{ipsiA} / \mathrm{ipsiH}$ & -0.22 & -0.19 & -0.08 & -0.07 & 0.06 & -0.01 \\
\hline$\angle \mathrm{ipsiP} / \mathrm{ipsiH}$ & -0.21 & -0.04 & 0.15 & $-0.26^{*}$ & 0.07 & 0.01 \\
\hline$\angle \mathrm{ipsiA} / \mathrm{ipsiP}$ & 0.10 & 0.01 & 0.03 & -0.14 & 0.16 & -0.14 \\
\hline
\end{tabular}

JB, jugular bulb; Psag, median sagittal plane; Pcor, coronal plane; Pfrkt, Frankfurt horizontal plane; L, left; R, right; ipsi, ipsilateral.

$\angle$ indicate angle between 2 planes; A, H, and P indicate the anterior, horizontal, and posterior semicircular canal plane, respectively; JB-Psag, JB-Pcor, and JB-Pfrkt: The JB position in the cranial base was defined as its distances from Psag, Pcor, and Pfrkt planes, respectively.

${ }^{*} P<0.05$.

Table 5. Angles between semicircular canals compared with reported results (degrees)

\begin{tabular}{lrcccccc}
\hline Source & No. & $\angle$ ipsiA/ipsiH & $\angle$ ipsiA/ipsiP & $\angle$ ipsiP/ipsiH & $\angle$ rightH/leftH & $\angle$ rightA/leftP & $\angle$ leftA/rightP \\
\hline Current & 76 & $88.3 \pm 5.1$ & $110.3 \pm 8.8$ & $87.6 \pm 4.8$ & $8.6 \pm 4.9$ & $19.0 \pm 7.2$ & $19.0 \pm 7.8$ \\
El Khoury et al. [10] & 137 & $74.2 \pm 4.4$ & $111.2 \pm 6.4$ & $88.2 \pm 6.2$ & $19.7 \pm 8.9$ & $10.6 \pm 5.4$ & $11.4 \pm 6.4$ \\
Aoki et al. [11] & 11 & $91.5 \pm 6.7$ & $94.9 \pm 3.8$ & $91.0 \pm 4.9$ & $9.8 \pm 5.1$ & $17.2 \pm 9.5$ & $19.0 \pm 8.8$ \\
Blanks et al. [2] & 12 & $111.8 \pm 7.6$ & $86.2 \pm 4.7$ & $95.8 \pm 4.7$ & $19.8 \pm 14.9$ & $23.7 \pm 6.7$ & $24.6 \pm 7.2$ \\
\hline
\end{tabular}

Values are presented as mean \pm SD.

ipsi, ipsilateral.

$\angle$ indicate the angle between 2 planes; $\mathrm{A}, \mathrm{H}$, and $\mathrm{P}$ indicate the anterior, horizontal, and posterior semicircular canal plane, respectively.

now, several articles have discussed the geometrical features of semicircular canals in humans and other primates [13,14]. The orientation and angular relationships of semicircular canals which are critical to vestibular function had been studied extensively. Several researchers observed reorientation of semicircular canals with increasing human fetal age, and stabilized at about 22 weeks of gestational age $[5,15]$. It is unclear whether the environmental and behavioural factors such as surrounding structures development and bipedalism postnatally influence the semicircular canals orientation. To solve this problem, postnatal semicircular canals orientation was calculated and compared in the studied subjects of different age groups.

The semicircular canals are frequently depicted as a mutually orthogonal collection of communicating canals [16]. However, pairs of ipsilateral semicircular canal were rarely perpendicular $[2,17]$. Angles between anterior and ipsilateral posterior canal pairs were also found to significantly deviate from orthogonality by about 20 degree in our study. As the angles between semicircular canals are independent of the choice of coordinate systems, our calculation results of these angles were comparable to previous published results. As seen in Table 5, our calculation results were very similar to those of Aoki et al. [11].Therefore, the calculation method we used was reliable and effective.

The differences in the method of mapping semicircular canals can contribute to the different findings between studies. Much difference was found between our calculation results and those of Blanks et al. [2] who excluded the common crus and ampullae from measurement. The angles between opposite synergisti- 
cally acting canal planes in our study were smaller than theirs. Compared with the study by El Khoury et al. [10] who did not include the ampullae into calculation, angles between bilateral horizontal canal planes were smaller, while angles between other opposite synergistically acting canals were larger in our study. Jeffery and Spoor [5] found that the human horizontal canal tilted antero-inferiorly relative to the cranial base, in association with a coronal reorientation of the petrous bones with increasing fetal age. Besides, they also found the angle between anterior and ipsilateral posterior canals continued to open laterally until the ossification of the surrounding otic capsule finished $[5,15]$. Due to the functional constraints, planar orientations of the semicircular canals are always thought to be conserved. However, there are maybe some postnatal developmental or behavioural factors which can influence the position and orientation of semicircular canals. In our study, we found the semicircular canals tilted anteriorly simultaneously as a whole with age without significant changes in the orientational relationships between ipsilateral semicircular canals. These changes correlated to the postnal development of JB, but did not correlate to the temporal bone pneumatization. Whether there is an association between those postnatal changes and head posture changes in human movement from crawling to walking is still unclear. Perhaps the head tilts back with age to compensate for the anterior tilt of semicircular canals. This assumption need to be studied in future with calculating the spine.

The JB is the largest and nearest blood vessel adjacent to the semicircular canals. The anteroposterior position of right JB correlated to both anterior semicircular canal orientation and angles between ipsilateral posterior and horizontal canals. However, much less correlations were found between the left JB position and the spatial arrangement of semicircular canals. This may be due to the more morphological variability of JB and higher incidence of high JB on the right side than those on the left side [18-20].

The semicircular canals orientation helps determine the vestibular function. Berlin et al. [17] demonstrated that species with greater deviations from canal orthogonality, angle symmetry and coplanarity of synergistic canal pairs tended to have lower sensitivity to angular accelerations and to experience slower head rotations during locomotion. However, our calculation results showed a little difference in the coplanarity of synergistic canals and no differences in the canal orthogonality (angles between ipsilateral semicircular canal planes) between age groups. These results imply that the postnatal changes in the angles between semicircular canals may not affect the vestibular function. Although we found the semicircular canals had tendencies to tilt anteriorly simultaneously as a whole relative to the cranial base with age during postnatal development, the relationship between their anterior tilt and the vestibular sensitivity could not be proved by this study alone because of the lack of vestibular functional data. Whether a relationship between them exists need to be tested by a long-term prospective study.

The calculation methods, including ours, might enable the detection of pathological changes in vestibular morphology in a variety of diseases, such as vertigo and congenital inner ear abnormities, and contribute to the understanding of the etiopathogenesis of certain diseases. For example, the adolescent idiopathic scoliosis patients who have poor postural balance control are reported to have smaller distance between centers of lateral and superior canals and angle with vertex at the center of posterior canal [21]. The link between the vestibular anatomical change and the vestibular dysfunction is still poorly understood. The change in semicircular canals orientation might affect the flow dynamics of endolymph within them, which then affect the sensory hair cells and finally affect the perceptive sensitivity of the canal system.

The current methodology for semicircular canal morphology analysis is limited as the linear and angular measurement is difficult to explicitly depict the complicated topological features of semicircular canals. Besides, different sex ratios of each group and the small sample size of group $\mathrm{C}$ might increase the sampling error and affect the quality of the statistical analytical results to a certain extent.

In conclusion, the semicircular canals had tendencies to tilt anteriorly simultaneously as a whole with age. The JB position correlated to the spatial arrangement of semicircular canals, especially the right JB. Our study helps depict the orientational changes in semicircular canals during postnatal development. The calculation method in this paper may enable the detection of pathological changes in vestibular anatomy.

\section{CONFLICT OF INTEREST}

No potential conflict of interest relevant to this article was reported.

\section{ACKNOWLEDGMENTS}

This research was supported by the Program for Changjiang Scholars and Innovative Research Team in Universities (IRT1010) and Shanghai Science and Technology Committee (12ZR1441900).

\section{REFERENCES}

1. Bradshaw AP, Curthoys IS, Todd MJ, Magnussen JS, Taubman DS, Aw ST, et al. A mathematical model of human semicircular canal geometry: a new basis for interpreting vestibular physiology. J Assoc Res Otolaryngol. 2010 Jun;11(2):145-59.

2. Blanks RH, Curthoys IS, Markham CH. Planar relationships of the 
semicircular canals in man. Acta Otolaryngol. 1975 Sep-Oct;80 (3-4):185-96

3. Ifediba MA, Rajguru SM, Hullar TE, Rabbitt RD. The role of 3-canal biomechanics in angular motion transduction by the human vestibular labyrinth. Ann Biomed Eng. 2007 Jul;35(7):1247-63.

4. Yang A, Hullar TE. Relationship of semicircular canal size to vestibular-nerve afferent sensitivity in mammals. J Neurophysiol. 2007 Dec; 98(6):3197-205.

5. Jeffery N, Spoor F. Prenatal growth and development of the modern human labyrinth. J Anat. 2004 Feb;204(2):71-92.

6. McRackan TR, Reda FA, Rivas A, Noble JH, Dietrich MS, Dawant $\mathrm{BM}$, et al. Comparison of cochlear implant relevant anatomy in children versus adults. Otol Neurotol. 2012 Apr;33(3):328-34.

7. Scott JH.The cranial base.Am J Phys Anthropol. 1958 Sep;16(3):319 48.

8. Barbeito-Andres J, Ventrice F, Anzelmo M, Pucciarelli HM, Sardi ML. Developmental covariation of human vault and base throughout postnatal ontogeny. Ann Anat. 2015 Jan;197:59-66.

9. Lee ST, MoriY, Minami K, An CH, Park JW, KwonTG. Does skeletal surgery for asymmetric mandibular prognathism influence the soft tissue contour and thickness? J Oral Maxillofac Surg. 2013 Sep; 71(9):1577-87.

10. El Khoury M, Braga J, Dumoncel J, Nancy J, Esclassan R, Vaysse F. The human semicircular canals orientation is more similar to the bonobos than to the Chimpanzees. PLoS One. 2014 Apr;9(4): e93824.

11. Aoki S, Takei Y, Suzuki K, Masukawa A, Arai Y. Planer orientation of the bilateral semicircular canals in dizzy patients. Auris Nasus Larynx. 2012 Oct;39(5):451-4.

12. Kopelman M, Glik A, Greenberg S, Shelef I. Intracranial nonjugular venous pathways: a possible compensatory drainage mechanism. AJNR Am J Neuroradiol. 2013 Jul;34(7):1348-52.

13. Sato H, Sando I,Takahashi H, Fujita S. Torsion of the human semicircular canals and its influence on their angular relationships. Acta Otolaryngol. 1993 Mar;113(2):171-5.

14. Gunz P, Ramsier M, Kuhrig M, Hublin JJ, Spoor F. The mammalian bony labyrinth reconsidered, introducing a comprehensive geometric morphometric approach. J Anat. 2012 Jun;220(6):529-43.

15. Mejdoubi M, Dedouit F, Mokrane FZ, Telmon N. Semicircular canal angulation during fetal life: a computed tomography study of $54 \mathrm{hu-}$ man fetuses. Otol Neurotol. 2015 Apr;36(4):701-4.

16. Suzuki K, Masukawa A, Aoki S, Arai Y, Ueno E. A new coordinates system for cranial organs using magnetic resonance imaging. Acta Otolaryngol. 2010 May;130(5):568-75.

17. Berlin JC, Kirk EC, Rowe TB. Functional implications of ubiquitous semicircular canal non-orthogonality in mammals. PLoS One. 2013 Nov;8(11):e79585.

18. Friedmann DR, Eubig J, McGill M, Babb JS, Pramanik BK, Lalwani AK. Development of the jugular bulb: a radiologic study. Otol Neurotol. 2011 Oct;32(8):1389-95.

19. Dai PD, Zhang HQ, Wang ZM, Sha Y,Wang KQ, Zhang TY. Morphological and positional relationships between the sigmoid sinus and the jugular bulb. Surg Radiol Anat. 2007 Dec;29(8):643-51.

20. Woo CK, Wie CE, Park SH, Kong SK, Lee IW, Goh EK. Radiologic analysis of high jugular bulb by computed tomography. Otol Neurotol. 2012 Sep;33(7):1283-7.

21. Shi L, Wang D, Chu WC, Burwell GR, Wong TT, Heng PA, et al.Automatic MRI segmentation and morphoanatomy analysis of the vestibular system in adolescent idiopathic scoliosis. Neuroimage. 2011 Jan;54 Suppl 1:S180-8. 